\title{
UMA DISCUSSÃO PRELIMINAR SOBRE A SEGURANÇA PÚBLICA NUMA PERSPECTIVA ERGOLÓGICA
}

\author{
A PRELIMINARY DISCUSSION ON PUBLIC SECURITY FROM AN ERGOLOGICAL \\ PERSPECTIVE
}

\author{
UNA DISCUSIÓN PRELIMINAR SOBRE SEGURIDAD PÚBLICA DESDE UNA \\ PERSPECTIVA ERGOLÓGICA
}

\author{
Sirley Aparecida Araújo Dias ${ }^{i}$ \\ Núbia Braga Ribeiro ii
}

\begin{abstract}
Resumo: A cidadania e a dignidade da pessoa humana, entre outros, são tratadas como como fundamento no Art. $1^{\circ}$ da Constituição Federal (CF/1988). Por sua vez, a segurança pública é evocada como uma base para promover a cidadania e aqui já se articulam dois elementos que, longe de se distanciarem, deveriam ser aproximar, conquanto um seja fundamento do outro. A discussão da segurança pública à luz dos conceitos ergológicos, notadamente do Espaço Tripolar, conforme previsto por Durrive e Schwartz (2010) engendra polos que evidenciam as aproximações e as tensões entre essas instâncias. Nesse sentido, o campo de pesquisas da segurança pública e da cidadania tem muito a contribuir no aprofundamento dos conceitos, na produção e uniformidade de conhecimento e na formação continuada dos diversos atores envolvidos na segurança pública. Dessa forma esperase também contribuir para o alcance efetivo da cidadania conforme preconizado na CF/1988.
\end{abstract}

Abstract: Citizenship and the dignity of the human person, among others, are treated as a foundation in Article 1 of the Federal Constitution (CF / 1988). In turn, public security is evoked as a basis for promoting citizenship and here two elements are already articulated that, far from distancing themselves, should be brought together, although one is the foundation of the other. The discussion of public security in the light of ergological concepts, notably from the Tripolar Space, as predicted by Durrive and Schwartz (2010) engenders poles that show the similarities and tensions between these instances. In this sense, the field of research on public security and citizenship has a lot to contribute in the deepening of concepts, in the production and uniformity of knowledge and in the continuous training of the various actors involved in public security. Thus, it is also expected to contribute to the effective reach of citizenship as recommended in CF / 1988.

Resumen: La ciudadanía y la dignidad de la persona humana, entre otros, se tratan como fundamento en el Artículo 1 de la Constitución Federal (CF / 1988). A su vez, la seguridad pública se evoca como base para promover la ciudadanía y aquí ya se articulan dos elementos que, lejos de distanciarse, deberían reunirse, aunque uno es la base del otro. La discusión de la seguridad pública a la luz de los conceptos ergológicos, en particular del Espacio Tripolar, según lo previsto por Durrive y Schwartz (2010) engendra polos que muestran las similitudes y tensiones entre estos casos. En este sentido, el campo de investigación sobre seguridad pública y ciudadanía tiene mucho que aportar en la profundización de conceptos, en la producción y uniformidad del conocimiento y en la formación continua de los diversos actores involucrados en la seguridad pública. Por lo tanto, también se espera que contribuya al alcance efectivo de la ciudadanía como se recomienda en CF / 1988.

Palavras-chave: Cidadania. Ergologia. Espaço-Tripolar. Segurança Pública.

Keywords: Citizenship. Ergology. Space-Tripolar. Public security.

Palabras claves: Ciudadanía. Ergología. Espacio-tripolar. Seguridad Pública. 
No Brasil a Constituição Federal (CF), promulgada em 1988, em seu preâmbulo, destaca a importância de um “ (...) Estado Democrático, destinado a assegurar o exercício dos direitos sociais e individuais, a liberdade, a segurança, o bem-estar, o desenvolvimento, a igualdade e a justiça como valores supremos de uma sociedade fraterna, pluralista e sem preconceitos". Para tanto trata como fundamento, em seu Art. $1^{\circ}$., entre outros, da cidadania e a dignidade da pessoa humana.

Da mesma forma, a CF trata da segurança pública como uma base para promover a cidadania. Cabe aqui um ponto de reflexão de que não haveria cidadania plena sem a segurança pública. Essa, por sua vez, é exercida pelo Estado no conjunto das garantias fundamentais do contrato social que pauta as relações humanas à luz dos direitos e deveres em relação à liberdade, à política e à vida em sociedade.

Desde 2016, o Brasil tem vivido momentos críticos acerca do cumprimento do papel do Estado previsto em matéria constitucional. Há retrocessos evidentes nas políticas públicas, na proteção e garantias do Estado nas áreas da educação, saúde, segurança pública, entre outras. Nesse cenário conturbado é preciso chamar ao debate o papel da segurança pública, que não deveria ser negligenciado, muito menos relativizado, posto que se trata de um preceito constitucional.

A abordagem ergológica fornece insumos para discutir o papel do Estado e suas ações em segurança pública. O presente artigo pretende, de forma preliminar, discutir algumas noções ergológicas, notadamente aquelas que permitem pensar a gestão como um problema propriamente humano, possibilitando refletir sobre possíveis contribuições da ergologia para o campo da segurança pública. Cumpre ressaltar que nessa abordagem o trabalho é tomado do ponto de vista da atividade ${ }^{1}$ e que também é feita uma articulação com o esquema denominado "Espaço Tripolar" conforme preconizado por Schwartz; Durrive (2010).

Dessa perspectiva o trabalho não pode ser reduzido à sua tarefa e visto como algo a ser gerido de fora e de forma prescritiva. Uma vez que como já demonstrado pelos ergonomistas de orientação francesa, o trabalho humano não se restringe à sua prescrição. A distinção entre trabalho real (atividade) e trabalho prescrito (tarefa) parece central para se pensar em qualquer gestão do trabalho.

\footnotetext{
1 A utilização do termo 'atividade' (no singular) se reveste de particular importância por colocar em relevo o que o sujeito leva em conta para executar seu trabalho. Por sua vez a palavra 'atividades' (no plural) é aqui utilizada em sua forma usual, conforme seu entendimento para o senso comum e também é mantida quando se localizar dentro das citações diretas dos autores.
} 
Embora não seja possível, nesse momento, detalhar os aspectos relativos à atividade do profissional da segurança pública, essa é uma abordagem que será trabalhada na formação dos discentes o âmbito do Mestrado Profissional em Segurança pública. Trata-se um programa de pós-graduação Stricto sensu em sua primeira oferta na Universidade do Estado de Minas Gerais (UEMG) com início das atividades em Agosto de 2019.

O Curso de Mestrado Profissional em Segurança Pública e Cidadania é o primeiro curso de Mestrado em Segurança Pública no Estado de Minas Gerias e o quarto do país. Embora o tema da segurança pública seja tão relevante para a sociedade, a participação das universidades para enfrentamento deste problema é irrisória em um país continental como o Brasil. A FIGURA 01 apresenta o Atlas da Violência de 2019 trazendo dados contundentes sobre a violência no Brasil e assevera de forma inequívoca a necessidade de que esse fenômeno seja estudado e debatido para que possam ser produzidas alternativas e estratégias para lidar com esse problema social.

Figura 01 - Mapa da violência 2019

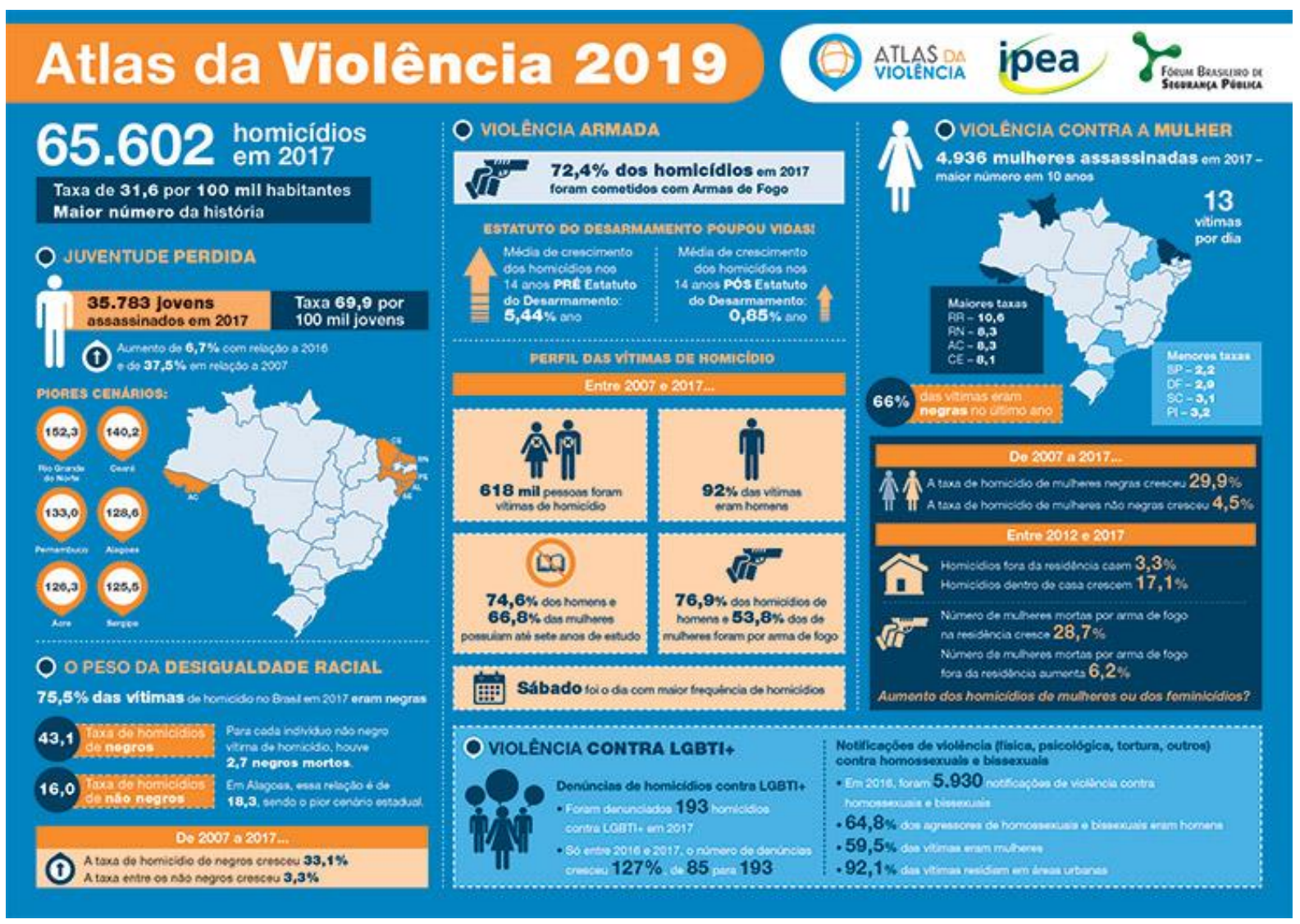

Fonte: IPEA (2019)

É fundamental a abordagem sobre os fenômenos presentes na reflexão sobre a segurança pública, a cidadania, o crime e as violências cotidianas. Esses fenômenos 
perpassam as relações sociais e mobilizam a opinião pública e os atores responsáveis pela segurança pública, de forma objetiva ou subjetiva. O crime como fato social e as violências são vistos como fenômenos múltiplos que atingem a população independentemente de classe, raça/etnia, credo religioso, sexo ou estado civil. Os crimes e a violência repercutem tanto no imaginário cotidiano das pessoas, quanto na necessidade de investimentos e recursos destinados ao enfrentamento da questão.

É nesse sentido que se destaca a relevância do tema segurança pública aqui brevemente apresentado. A Universidade pode e deve contribuir significativamente no aprofundamento dos conceitos e na produção e uniformidade de conhecimento na formação continuada das diversas entidades envolvidas na segurança pública considerando a grande preocupação da população com o tema e auxiliando efetivamente na cidadania prevista na CF.

\section{A SEGURANÇA PÚBLICA E O ESPAÇO TRIPOLAR}

Tomando a ergologia como pressuposto teórico para se discutir a relação entre a sociedade, as organizações e o trabalho do ponto de vista da atividade por meio do espaço tripolar. Ao proporem um esquema que apresente o esquema do espaço tripolar, Durrive e Schwartz (2010) advertem que não querem designar espaços estanques nem independentes; ao contrário, querem evidenciar toda a circulação existente entre os polos. Assinalam ainda que entre esses polos há "uma gama de situações intermediárias, não cabendo, portanto, encaminhar um raciocínio segmentado ou dicotômico" (Ibidem, 247). Dito isso, é preciso distinguir cada um dos polos, para melhor evidenciar as circulações existentes entre esses. Os autores afirmam que, mesmo correndo risco da simplificação que um esquema pode trazer, o espaço tripolar quer "situar as relações dialéticas extrema e permanentemente tensas, para tentar pensar as matrizes da história” (Ibidem, p. 253).

O polo mercantil compreende as relações comerciais que, por excelência, estão voltadas para a circulação econômica e, para segmentos econômicos. Diz respeito às dimensões quantificáveis e sua repercussão no cotidiano das pessoas. Se tomado o mundo do trabalho, o polo mercantil é o espaço de circulação do consumo, da remuneração da atividade humana, evidenciando as trocas mercantis. Na outra extremidade do espaço tripolar, estão os valores que não se mensuram de forma quantificável e não constituem parâmetros precisos, embora ninguém ignore sua importância. A apresentação do espaço coloca uma "polaridade problemática" entre os dois, permitindo refletir sobre o que os autores denominaram de sociedade mercantil e sociedade de direito. 
Sociedade mercantil: sociedades nas quais justamente o peso do mercado e o fato de se utilizar a atividade humana sob o enquadramento de atividades mercantis são aspectos fundamentais e que perturbam incessantemente a vida cotidiana pelo mundo afora;

Sociedade de direito: ao mesmo tempo trata-se de sociedades - não por todo o planeta e com variações consideráveis entre princípios e realidades - nas quais existe um código de direito para regular as relações entre os homens, como instituições, constituições, mais frequentemente o sufrágio universal, em que cada um é igual; em que, portanto, todos esses valores que mencionei são objeto de debates democráticos (SCHWARTZ; DURRIVE, 2010, p. 248).

Os dois polos, apesar de terem uma compatibilidade eminentemente problemática, estão sempre interagindo, embora sejam orientados por diferentes lógicas de criação de meios de vida. O polo mercantil se orienta em função dos valores quantificáveis, do movimento financeiro, do que se produz ou se obtém em valores financeiros, sendo, portanto, dimensionáveis (SCHWARTZ; DURRIVE, 2010). De outra parte, no polo da sociedade de direito, as questões versam sobre o que não é quantificável, se referem aos valores, colocando dificuldades objetivas, por exemplo, qual o peso a ser dado ao valor "como viver bem juntos", a importância da saúde, da cultura, entre outros. Enfim, não se trata de um "universo pacífico", livre de problemas; ao contrário, é um lugar de debates e tensões. "E tais valores, em sua origem, não são dimensionáveis. O problema, efetivamente, é que a vida nos obriga a introduzir essa história desses valores sem dimensão" (SCHWARTZ; DURRIVE, 2010, p. 249) (itálicos no original). A FIGURA 02 apresenta a configuração do esquema do Espaço Tripolar.

FIGURA 2: Espaço Tripolar

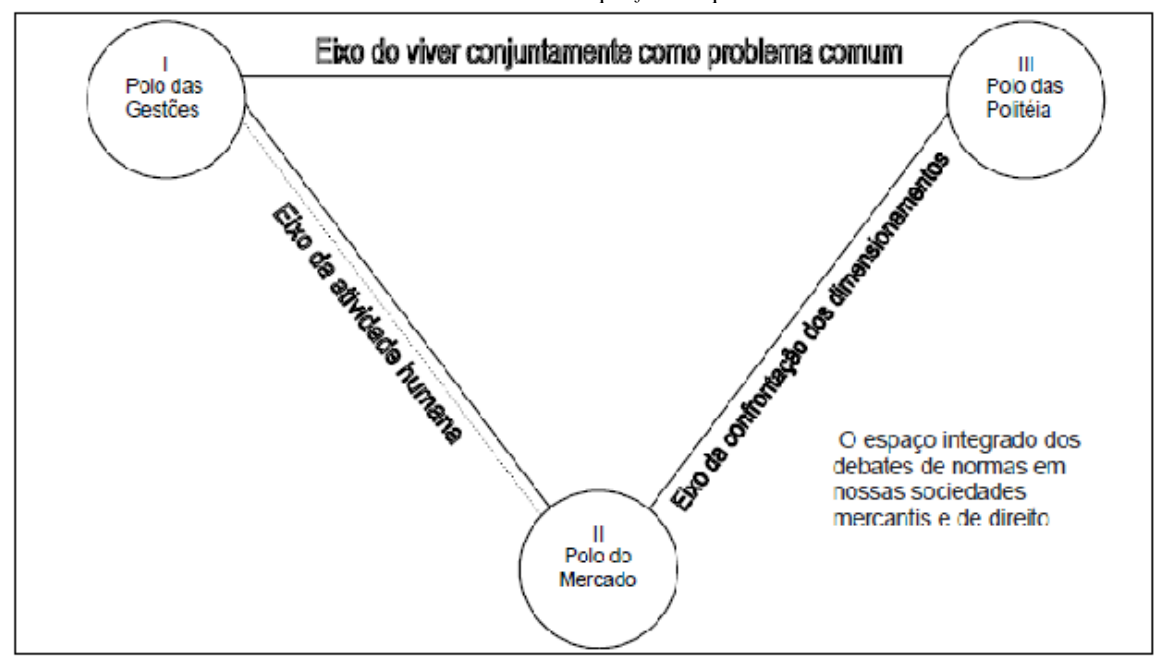

Fonte: Schwartz (2010) adaptado por Dias (2015) 
Posto que não sejam polos antagônicos, mas se situam em posições opostas, existem recomposições em curso. Os autores se interrogam até que ponto, por meio dessa circulação, os valores de um dos polos acabam sendo trabalhados pelos valores do outro. Se há concordância de que existem valores operando, da mesma maneira instaura-se um debate permanente. Os autores argumentam que existe troca de valores e que isso se opera numa conjuntura política no interior de uma instância que possa encaminhar o que é colocado por essas polaridades. Ao se refletir sobre os valores sem dimensão, por exemplo, a saúde é um valor para o bem comum, mas isso tem um custo a ser pago em alguma instância, seja pública, privada ou em ambas.

Conquanto nessa bipolaridade não aparece, o espaço em que homens e mulheres operam e fazem ou participam da história. É precisamente aí, onde se tem a impressão de que não há qualquer possibilidade de as pessoas intervirem em instâncias tão definidas, que se instaura o eixo da atividade humana. "Entre o polo do mercado e o polo da cidade, falta um polo para dar conta das tensões nas quais a história se faz" (SCHWARTZ; DURRIVE, 2010, p. 250).

A configuração do espaço tripolar, ao inserir o polo das gestões, da atividade humana em primeiro plano, reafirma que "sem esse polo das gestões, não se sabe muito bem quem pensa, quem sofre, quem quer mudar, e onde é o lugar dos debates de normas e de valores" (Ibidem, p. 253). A se desconsiderar a existência de tal polo, ignora-se o fato de que os seres humanos fazem história em sua atividade humana.

A ideia do esquema comporta pensar nas tensões e relações que se estabelecem entre eles. "Cada polo tem a sua especificidade profunda, mas, ao mesmo tempo, seria ininteligível em si, em sua vida, em sua duração, nos seus debates, fora do contexto da relação com os outros dois polos" (Ibidem, p. 253).

Os polos II e III, o mercantil e o político, do direito, do bem comum, dos valores que todo cidadão reivindica, "têm relações e pontos comuns, ao mesmo tempo em que são perpassados por fortes tensões. O que há de comum entre esses dois polos é o fato de produzirem normas antecedentes" (Ibidem, p. 254).

O polo III abrange o campo do político, dos valores sem dimensão, das instituições, das ações dos políticos. E, tanto para o polo II quanto para o polo III, "são necessárias regras, normas, hierarquias” (Ibidem, p. 254) (itálicos no original).

O espaço tripolar fornece subsídios para pensar a atividade humana no enquadramento social, cultural, legal, jurídico e econômico, uma vez que as circulações que vão ocorrer nesse espaço precisam do encontro com as dialéticas. No encontro, nas 
recomposições do Polo I, é que se dão "aquilo que chamamos de re-singularizações, recentramentos, considerando essa espécie de dialética permanente do impossível e do invivível, que se trava no nível desse polo" (Ibidem, p. 254).

\section{ESTABELECENDO RELAÇÕES ENTRE OS CONCEITOS}

Retoma-se a proposta original desse artigo, qual seja, a partir de fundamento constitucional da cidadania, dignidade humana e da segurança pública e a sua articulação com algumas noções ergológicas, mais propriamente com o esquema denominado "Espaço Tripolar" conforme preconizado por Schwartz; Durrive (2010) para estabelecer as relações e interpelações entre os temas.

Assume-se que "a história está sendo feita nesse momento, ou seja, a atualidade nos está mostrando que a sociedade está envolvida em debate de normas, em debate de valores, experimenta crises permanentes entre o econômico, o político e o jurídico e com o mundo do trabalho" (SCHWARTZ; DURRIVE, 2010, p. 247).

Assim o denominado espaço tripolar remete a qualquer aspecto da vida, em qualquer lugar do mundo e que a configuração desse esquema possibilita relacionar dois níveis de apreensão do cotidiano e de história: do plano mais micro ao mais macroscópico. No presente caso, o Polo III se relaciona com toda legislação que emana do político, do bem comum, dos valores sem dimensão. Tais características são particularmente fortes no setor público, onde é esperado que sua atuação seja voltada às demandas da sociedade. Aqui se situa a "Gestão dos serviços públicos”, conforme previsto no Polo III, “ polo ‘do direito’ ou do político, dos organismos da democracia, que oficialmente encarrega-se do que chamamos de 'valores sem dimensão', em nome dos cidadãos" (Ibidem, p. 253) e a segurança dos cidadãos encontra apoio nessa premissa. Na segunda dimensão que corresponde ao Polo II estão localizadas as organizações que irão se pautar pelas definições emanadas do Polo III e cabe aí uma gama de situações intermediárias.

Como se trata de "Gestão dos Serviços Públicos", não se fala de algo homogêneo ou uniforme. Ao se tomar nas instituições públicas, no caso a segurança, há uma demanda pelos 'valores sem dimensões' tanto quanto a saúde e a educação, por exemplo. Fato é que não há uniformidade nas instituições e por isso já se começa a delinear que as orientações emanadas pelo Polo III terão que ser traduzidas, por assim dizer, para a realidade daquela instituição específica. O Polo II denominado Polo do Mercado, não necessariamente precisa ser mercantil, mas também conta com valores dimensionáveis. Precisamente aí se instala uma organização, uma instituição ou um serviço público. Nesse Polo é possível quantificar os 
atendimentos, o cumprimento do planejamento ou daquilo que foi solicitado por outras instâncias ou por normas antecedentes, como por exemplo, o orçamento definido para um programa, uma ação ou uma medida social.

Novamente se constata a lacuna entre trabalho prescrito e trabalho real e é preciso um Polo para dar conta da atividade humana, que é o Polo I. Nas peculiaridades do que é o serviço público é possível apontar para as eventuais dificuldades da gestão desse Polo. E, também nesse caso, quem vai dar conta da realização de algo é o sujeito que está envolvido na situação, uma vez que o trabalho humano não é feito de forma mecânica ou automática. Essas, entre outras, são peculiaridades que se apresentam no setor público e que demandam a gestão do trabalho humano conforme preconiza o esquema do espaço tripolar. É no infinitesimal da atividade é que se pode perceber como é feita essa gestão cotidiana e permanente para que se obtenha êxito no que foi definido por instâncias exteriores aos servidores.

Reconhecendo as limitações do presente trabalho e, apesar disso, considerando o início do Mestrado Profissional, as pesquisas vindouras contribuirão para o desenvolvimento do (re)conhecimento da atividade do servidor na área de segurança pública, de forma a relatar seus avanços, impasses e aprendizados.

\section{REFERÊNCIAS}

BRASIL, IPEA (Instituto de Pesquisa Econômica Aplicada). Atlas da violência 2019. Organizadores: Instituto de Pesquisa Econômica Aplicada; Fórum Brasileiro de Segurança Pública. Brasília: Rio de Janeiro: São Paulo: Instituto de Pesquisa Econômica Aplicada; Fórum Brasileiro de Segurança Pública. Disponível em http://www.ipea.gov.br/portal/images/stories/PDFs/relatorio institucional/190605 atla

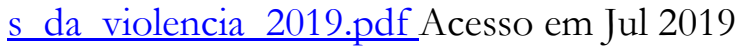

BRITO, Jussara Cruz de. Trabalho Prescrito. In: PEREIRA, Isabel Brasil \& LIMA, Júlio César França (org). Dicionário da educação profissional em saúde. 2.ed. rev. ampl. - Rio de Janeiro: EPSJV, 2008. Disponível em:

http://www.epsjv.fiocruz.br/dicionario/apresentacao/dowlivfictec.html

DIAS, S. A. A. Gestão da Carga de Trabalho nas Nervuras do Ofício Docente no Ensino Superior Privado. Tese (Doutorado em Educação) - Universidade Federal de Minas Gerais, Belo Horizonte, 2015.

SCHWARTZ, Y. Trabalho e gestão: níveis, critérios, instâncias. In Figueiredo, M., Athayde, M., Brito, J.,\& Alvarez, D. (Orgs.), Labirintos do Trabalho. Rio de Janeiro: DP\&A. 23-33 (2004a).

SCHWARTZ, Y. \& DURRIVE, L. (Orgs.). Trabalho e Ergologia: conversas sobre a atividade humana. Niterói: EdUFF, 2010. 
i Doutorado em Educação - Linha de Pesquisa Política, Trabalho e Formação Humana pela Universidade Federal de Minas Gerais (UFMG - 2015). Mestrado em Engenharia de Produção - Linha de Pesquisa Organização do Trabalho pela Universidade Federal de Minas Gerais (UFMG - 2007). Graduação em Serviço Social pela Pontifícia Universidade Católica de Minas Gerais (PUC Minas - 1987). Professora Efetiva da Universidade do Estado de Minas Gerais (UEMG). Coordenadora-adjunta do Mestrado Profissional em Segurança Pública e Cidadania da Faculdade de Políticas Públicas da Universidade do Estado de Minas Gerais (UEMG). Tem interesses de pesquisas nas áreas de Educação, Gestão de Pessoas, Ergonomia, Ergologia, Políticas Públicas, Segurança Pública e Trabalho. E-mail: sirley.dias@uemg.br

ii Graduação em História pela Pontifícia Universidade Católica de Minas Gerais - PUC-MINAS (1989), Mestre em História Social pela Universidade de São Paulo - USP-SP (1996) e Doutora em Ciências na área de História Social pela Universidade de São Paulo - USP-SP (2008). Atualmente, sou professora da Faculdade de Políticas Públicas "Tancredo Neves" (FaPP - UEMG) e Coordenadora do Mestrado Profissional em Segurança Pública e Cidadania na mesma Instituição. Fui Coordenadora do Curso de Pós-Graduação Lato Sensu em Gestão Pública na modalidade a distância do Programa PNAP/CAPES/MEC da Universidade Aberta do Brasil. Também coordenei o Curso de Pós-Graduação Lato Sensu em Gestão Pública para os Servidores da UEMG e para o público externo. Dedico-me aos temas de estudo que contemplam o campo da cidadania, dos direitos humanos, da segurança pública, das políticas públicas, da democracia, da participação social, da diversidade étnica e cultural, bem como as reflexões em torno da ética e da responsabilidade social, de suas concepções históricas e seus significados no mundo contemporâneo.. E-mail: nubia.ribeiro@uemg.br 